\title{
The Effects of Knowledge Sharing and Absorption on Organizational Innovation Performance - A Dynamic Capabilities Perspective
}

\author{
Fan-Yun Pai \\ National Changhua University \\ of Education, Changhua, \\ Taiwan
}

fypai@cc.ncue.edu.tw

\author{
Hung-Fan Chang \\ National ChiaoTung University, \\ Hsinchu City, \\ Taiwan
}

\begin{abstract}
Knowledge sharing and absorption are required to achieve and sustain competitive advantage. Firms' dynamic capabilities assist in mediating the effects of knowledge sharing and absorption on organizational innovation performance. Therefore, this study proposed a conceptual model to investigate the relationships among knowledge sharing capability, absorptive capability, dynamic capability, and organizational innovation performance. The partial least squares method was employed to examine the relationships. Questionnaire surveys were collected from the top 500 manufacturing companies in a typical emerging market, Taiwan. The results showed the positive effects of knowledge absorptive capabilities on dynamic capability and then on organizational innovation performance. In addition, the effects varied for companies with high and low innovation investment.
\end{abstract}

Keywords: Dynamic capabilities, Knowledge sharing, Absorptive capabilities, Organizational innovation performance.

\section{Introduction}

Innovation is the key path for an enterprise to sustain its competitive advantages (Matthyssens, Vandenbempt, \& Berghman, 2006; Orfila-Sintes \& Mattsson, 2009). Nowadays, as competition has been globalized, production cost is no longer different between companies, and innovation is the key to competitiveness. In addition, knowledge management and innovation activities are dynamic capabilities for organizations (Zollo \& Winter, 2002), and in order to survive in this era of

Material published as part of this publication, either on-line or in print, is copyrighted by the Informing Science Institute. Permission to make digital or paper copy of part or all of these works for personal or classroom use is granted without fee provided that the copies are not made or distributed for profit or commercial advantage AND that copies 1) bear this notice in full and 2) give the full citation on the first page. It is permissible to abstract these works so long as credit is given. To copy in all other cases or to republish or to post on a server or to redistribute to lists requires specific permission and payment of a fee. Contact Publisher@InformingScience.org to request redistribution permission. knowledge competition, an enterprise should have an efficient knowledge management system which can facilitate knowledge innovation and sharing and repetition (Chandran, 2004; Nonaka, 1991).

An organization acquires or develops a crucial index, which is whether the organization is capable to learn new knowledge during its adaptation to the 
environmental evolution (Peteraf, 1993). Teece (1986) believed that traditional competitiveness analysis is unable to evaluate an organization's organizational innovation performance and to guide its strategic direction in a fast changing environment, and thus he proposed the dynamic capabilities theory to help organizations in coordinating internal and external information to sustain their knowledge management systems and gain a competitive advantage. A firm needs to accumulate past experience and transform individual knowledge into organizational knowledge, and then, with the aid of continuous learning, the firm should develop the competence required to adapt to environmental changes. In addition integrating, transforming, and applying dynamic capabilities are crucial determinants of innovation (Helfat \& Peteraf, 2003). The main purpose of this paper is to observe how companies use dynamic capabilities to transfer knowledge management capabilities into organizational innovation performance.

The capability acquiring comes from knowledge absorptive capability. Cohen and Levinthal (1990) stated that absorptive capability is acquired by an organization on basis of existing knowledge, as well as by recognizing, absorbing, and using external knowledge. Zahra and George (2002b) further explained absorptive capability from the perspective of dynamic capability, and noted that absorptive capability is a set of processes for analyzing knowledge accumulation and transformation, and that it can lead to competitive advantage (Liao \& Wu, 2010; Tsai, 2010). That is, absorptive capability is sustained and created through the development of dynamic capability. Furthermore, knowledge sharing in an organization will increase its potential absorptive capability (Spender, 1996). This paper attempts to study the effects of dynamic capabilities on organizational innovation performance with an empirical approach, based on dynamic capabilities, knowledge sharing, and absorptive capability. The main purpose is to review knowledge management studies, focusing on the effects of dynamic capability, knowledge sharing, and absorptive capability on organizational innovation performance and to propose a conceptual model and hypotheses. Furthermore, we analyze different types of firms and their dynamic capabilities, knowledge sharing, and absorptive capabilities as well as their relationships with organizational innovation performance, and finally highlight the practical implications of the results for managers.

\section{Literature Review}

This section reviews studies on knowledge management, innovation and organizational innovation performance, dynamic capability, and knowledge absorptive capability It then develops a model to describe the relationships among knowledge management, dynamic capability and organizational innovation performance.

\section{Knowledge Management}

Knowledge creates a capability that enables firms to seize opportunities while analyzing information, and is crucial to achieve competitiveness (Liao \& Wu, 2010). However, only the advanced application of knowledge management can lead to a sustained competitive advantage. Knowledge management is widely applied to knowledge-based and learning organizations that seek to build a knowledge system based on all the available organizational information. The American Productivity \& Quality Center stated that knowledge management is a strategy to acquire appropriate knowledge, which assists in internal information sharing and improves organizational efficiency. Wiig (1997) proposed his Knowledge Management model with a principle that states that knowledge can be useful if it is well organized and used to improve efficiency and maximize profits. Roberts (2000) viewed knowledge management as "getting the right information to the right people at the right time to provide a competitive edge." Knowledge management is explicitly defined as a way to create and uncover knowledge, to make it concrete, and then to transfer and reutilize it (Demarest, 1997). We believe that classifying, storing, selecting, and using organizational 
knowledge will help companies to improve their profitability and competitiveness, and thus a successful knowledge management system plays an important role in a company's success.

In a fast moving and knowledge-based economy, technology can help customers save time in searching for substitutable product replacements (Liao \& Wu, 2010). Consequently, it is harder for companies to build and maintain a long term competitive advantage in this context. Organizational innovation performance in knowledge management consists of the application of various core competences and innovation activities that together form a company's core competitiveness. Along with customer innovation, firms create and transfer value through searching, filtering, classifying, reinforcing, integrating, and storing creative ideas. This paper aims to study the effects of an organization's dynamic capabilities on organizational innovation performance and to trace the causes and effects between organizational knowledge and competitive advantage.

\section{Knowledge Absorptive Capability}

The study of knowledge absorptive capability begins with Cohen and Levinthal's (1990) theory of absorptive capability. Cohen and Levinthal examined organization's absorptive capability from the perspective of acquisition and innovation. March and Simon (1958) noted that most innovative activities come from "borrowing" rather than "invention." Here, "borrowing" refers to observing knowledge or experiences from other organizations and creating new ideas, whereas "invention" means creating new ideas. Thus, based on the comments of March and Simon (1958), it seems that the capability of introducing new knowledge in the organization is a key factor to the innovation capability (Cohen \& Levinthal, 1990).

Cohen and Levinthal (1990) stated that an organization's existing related knowledge (like basic skills and common languages) will affect the recognition of knowledge value, knowledge assimilation, and usage. The capabilities to recognize knowledge value, and to assimilate and use knowledge, are known as absorptive capacity, which is defined as the capacity to acquire, recognize, assimilate, and use external knowledge on the basis of prior related knowledge.

Cohen and Levinthal (1990) defined absorptive capability as made up of three basic capabilities, which are recognizing useful external knowledge, understanding and assimilating the new knowledge, and applying it to commercial ends. Zahra and George (2002b) noted that most of the related empirical studies show that there is a positive correlation between knowledge absorptive and innovation capabilities and that together they can build a sustainable competitive advantage. They also suggested that absorptive capability is formed by potential absorptive capability and realized absorptive capability and that absorptive capability is a potential capability that allows a firm to gain, assimilate, transform, and use new information.

\section{Innovation and Organizational Innovation Performance}

Innovation is the gathering of ideas from internal and external customers and then producing valuable products or services, and it includes innovations related to technology, products, and processes (Tsai, 2010; Voss, 1992; Wingwon, 2012). Innovation behaviors may consist of internal process improvements, the development of new products, and novel strategic plans of product line management and organizational management. Johnson and Johnston (2004) differentiated organizational innovation performance from knowledge creation by stating that it is more focused on the product side and on the performance of new products with regard to the dimensions of market, cost and financial performance.

The creation of organizational innovation performance is based on a series of complicated innovation activities which form a value chain (Orfila-Sintes \& Mattsson, 2009; Tsai, 2010). Christensen, Kaufman and Shih (2008) noted that different types of innovation affect decision making behavior (strategic innovation), product development (product and process innovation), and tech- 
nical support mode (technical innovation). Storey, Emberson, Godsell, and Harrison (2006) pointed that the process of procurement, manufacturing, distribution, and servicing from supplier to consumer forms strategic innovation in the value chain. In addition, firms need external resources to complement the insufficiency of their internal techniques, and thus they will release and exchange their unused resources to external organizations and form interactive cooperate networks. In this regard, Chesbrough (2003) advised companies to commercialize their core techniques and sell, transfer or license their idle techniques to companies in order to create a new source of profits.

This paper focuses on the effects of organizational knowledge management and organizational innovation performance on the competitiveness and market acceptance of the organization. In this paper, the organizational innovation performance is measured with the following three common criteria: product innovation, process innovation, and profitable innovation.

\section{Dynamic Capabilities}

Teece, Pisano, and Shuen (1997) defined dynamic capabilities as a firm's ability to integrate, build, and reconfigure internal and external competences to address rapidly changing environments. Thus, dynamic capability can be seen as a way to obtain greater competitive advantages. Henderson and Cockburn (1994) further explained that dynamic capability is when a manager increases, abandons, integrates, or reconfigures resources in order to change the resource-based value and to create and develop new values. It is also a dynamic force that creates competitive advantage when associated with other resources. Zollo and Winter (2002) defined dynamic capabilities as a learned and stable pattern of collective activity through which the organization systematically generates and modifies its operating routines. Luo (2000) pointed out that dynamic capabilities include three essential ingredients: capability possession (distinctive resources), capability deployment (resource allocation), and capability upgrading (dynamic learning). Capabilities are increasingly updated through capability learning and building, and the creation, transformation, integration, and development of specific capabilities and resources will aid the realization of organizational strategies. Eisenhardt and Martin (2000) argued that dynamic capabilities are a set of processes that create, integrate, associate, and release resources, and that firms consolidate and allocate resources in order to fit or create market changes.

In sum, dynamic capabilities highlight the processes and the ability that an organization has to consolidate and transform its operating processes when facing environmental changes. Therefore, in this paper, dynamic capabilities are viewed as the abilities that an organization has to consolidate and coordinate its entire operating processes and to reallocate and transform them in the shortest time to respond to a rapidly changing environment.

\section{Research Hypotheses}

\section{Knowledge absorptive capability and dynamic capability}

According to Cohen and Levinthal (1990), acquired knowledge (for example, basic skills and common languages) will affect a firm's recognition of knowledge value, assimilation, and usage, and these are also known as an organization's "absorptive capacity." In sum, organizational learning and absorptive capability affect a firm's ability of knowledge acquisition and assimilation (Wingwon, 2012). Dynamic capabilities are defined as the abilities that a firm has to integrate, build and reallocate internal and external resources in order to respond to a rapidly changing environment. Therefore, we assume that if a firm increases absorptive capability, it will efficiently acquire external knowledge and quickly modify company strategy.

H1 : Potential absorptive capability positively affects dynamic capability. 
Knowledge transformation is the ability that an organization has to consolidate existing knowledge with new knowledge (Zahra \& George, 2002a). From an empirical perspective, it is to add new knowledge or to remove or reinterpret existing knowledge. The capacity of knowledge exploitation is the ability to introduce knowledge systematically into the organization after it has been transformed in order to modify, extend, and expand competitive capabilities (Zahra \& George, 2002a).

In brief, organizational learning and potential absorptive capability impact a firm's abilities of knowledge transformation and exploitation. Dynamic capabilities can be considered as a way to find new sources of competitive advantages. In addition, absorptive capability is a way to analyze organizational knowledge accumulation and circulation. The development of dynamic capabilities can efficiently create and sustain organizational competitive advantages. Therefore, in this paper, we assume that when realized absorptive capability is improved, dynamic capability will also be promoted so as to respond to the rapidly changing environment.

H2 : Realized absorptive capability positively influences dynamic capability.

Zahra and George (2002a) suggested that potential absorptive capability and realized absorptive capability are necessary, rather than sufficient, conditions to obtain organizational competitive advantage, and both of them are crucial to performance improvements. There is always gap between potential absorptive capability and realized absorptive capability. When the ratio of realized absorptive capability to potential absorptive capability is high, this means that the organization is able to use the acquired knowledge efficiently and that it positively affects the organization's performance. The gap between those two capabilities is influenced by the interorganizational social integrative system, which includes formal and informal knowledge sharing and affects an organization's knowledge transformation and exploitation capabilities (Spender, 1996).

In short, potential absorptive capability and realized absorptive capability constitute the necessary conditions for an organization to develop its competitive advantage. The more knowledge that is shared in an organization the higher the ratio of realized absorptive capability to potential absorptive capability. Therefore, we assume that there is significant positive correlation between realized absorptive capability and potential absorptive capability. In addition, the greater the knowledge sharing capability in an organization, the stronger the positive relationship between potential absorptive capability and realized absorptive capability.

H3 : Potential absorptive capability positively affects realized absorptive capability.

H4 : Knowledge sharing capability positively influences the relationship between potential absorptive capability and realized absorptive capability.

\section{Dynamic capability and organizational innovative performance}

Teece (1986) extended the dynamic capability concept from resource base, proposing that dynamic capability is the capability to change according to environmental changes. When the industrial environment changes rapidly and market competition is extremely fierce, dynamic capabilities emphasize the real-time response to the reconfiguration of resource capabilities in order to adapt to environmental changes (Teece et al., 1997). In sum, dynamic capability emphasizes a firm's responses to environmental changes. When industrial or technical improvements occur, market uncertainty will be significantly intensified, and thus, organizational innovative performance will be impacted by dynamic capabilities.

H5 : Dynamic capability positively affects organizational innovative performance. 


\section{Methodology}

The conceptual model is based on the relationships among dynamic capability, knowledge sharing, absorptive capability, and innovative performance. This study analyzes the data by the Structural Equation Modeling (SEM) method to verify hypotheses. This section presents the details of the research model, measurement application, research subjects, and data analysis. This paper applies knowledge management theory with organizational dynamic capability to examine the relationship between knowledge management and innovative performance. Based on the literature review, this study proposed five hypotheses and a conceptual model, as shown in Figure 1.

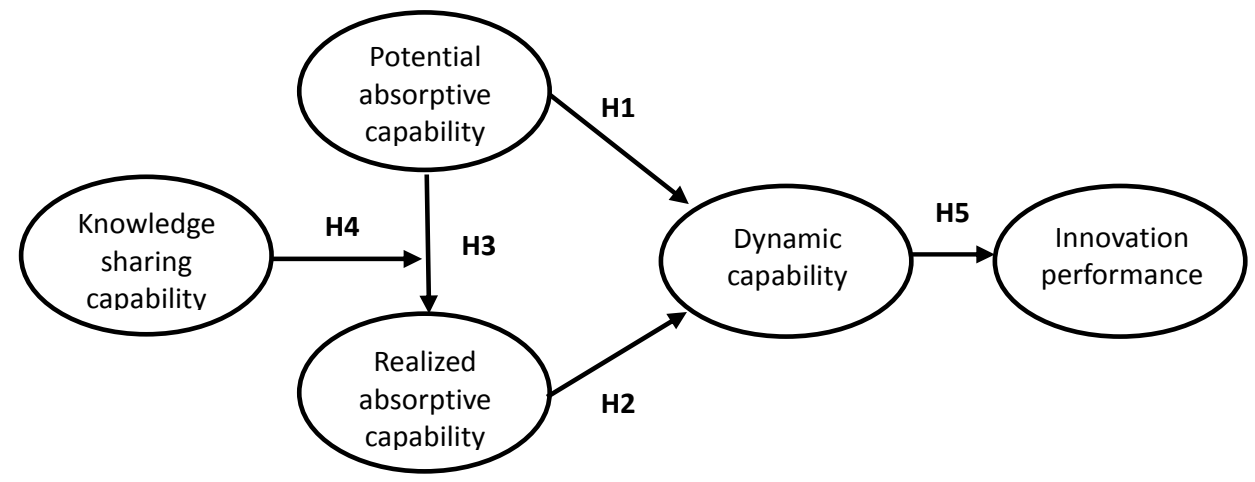

Figure 1. Conceptual model

A questionnaire was used to observe how knowledge management is applied in R\&D and related departments and to study the effects of dynamic capability on organizational innovative performance. The questionnaire covered five dimensions and contained 23 questions. The five dimensions are as follows:

1) potential absorptive capability (acquisition and assimilation);

2) realized absorptive capability (transformation and exploitation), based on Nonaka and Takeuchi (1995), Quinn, Anderson, and Finkelstein (1996), and Zahra and George's (2002a, 2002b) knowledge absorptive capability evaluation;

$3)$ knowledge sharing capability is based on the knowledge sharing and organizational innovation performance survey and knowledge sharing evaluation proposed by Dechant and Marsick (1993);

4) dynamic capability (integration and transformation) is based on Nonaka and Konno's (1998) dynamic capability studies and evaluation;

5) organizational innovation performance (product innovation, process innovation, and profit innovation) is based on Olson, Walker, and Ruekert (1995) and Cooper and Kleinschmidt's (1996) organizational innovation performance measurement.

Veugelers and Cassiman (1999) stated that analysis based on key sampling and a company's own internal information technically can ensure the feasibility and integrity of the data. Gan, Liow, Gupta, Lendermann, Turner, and Wang (2007) pointed out that analysis based on key sampling is applicable to specific industries for forecasting purposes. The top five hundred manufacturers in Taiwan are used as the research subjects. Top managements are invited to provide their opinions. We sent out 500 questionnaires and received 123 responses, giving a response rate of $24.6 \%$.

This paper uses Structural Equation Modeling (SEM) for data analysis, including path analysis and exploratory factor analysis, in order to analyze the relationships among the variables and fac- 
tors examined. In addition, the model proposed in this paper is verified by the Partial Least Squares (PLS) method, which is a statistical approach that probes or builds forecasting models. Unlike common forecasting models, PLS is able to deal with more than one set of prediction and response properties. $\mathrm{Wu}(2007)$ stated that PLS is a highly practical statistical method, as it can handle responsive and formative indexes simultaneously, which the traditional linear-based SEM LISREL technique cannot do.

The number of samples must be considered when the SEM method is applied. If the number of samples is insufficient, the goodness-of-fit, representativeness, and accuracy of the results will be adversely affected. According to Anderson and Gerbing (1988), the number of samples must be more than 200 in order to apply the SEM method in empirical studies, while Hayduk (1987) stated that 50 to 500 samples is the most appropriate, and if the number of samples is below 50, then convergence will not be achieved. Chin (1998) noted that PLS is a non-parametric statistics method, does not rely on any parameterized distributions, and will work with a relatively small sample size, such as 30-100. Zeng and Hsu (2008) mentioned that the PLS algorithm allows the iteration of explicit variables to calculate high level dimensions. Compared with LISREL, PLS does not require the normality and randomness of variables, and the path analysis does not need too many samples, and thus this paper uses this approach. Specifically, the SmartPLS software developed by Ringle, Wende, and Will (2005) from Hamburg University in Germany is used for SEM model structuring and data analysis.

\section{Empirical Analyses}

\section{Analysis of Reliability and Validity}

Cronbach's alpha coefficient is employed to measure reliability. According to Byrne (1994), a Cronbach's alpha coefficient above 0.7 indicates valid reliability. The validity measurement relies on the latent variables' composite reliability (CR) and average variance extracted (AVE) values. According to Fornell and Larcker (1981), a coefficient of CR value of 0.6 is an acceptable standard for normal composite reliability, and if it is above 0.7 then it is high composite reliability. AVE is the average amount of the variance of indicators that is explained by their corresponding latent variable. If the AVE is more than 0.5 , it means that the corresponding latent variable possesses convergent validity. Finally, $R^{2}$ is the explanatory power of the structural model path coefficient. The reliability and validity analyses of structural model are shown in Table 1.

Table 1: Reliability and validity analyses

\begin{tabular}{|c|c|c|c|c|}
\hline & AVE & $\begin{array}{l}\text { Composite } \\
\text { Reliability }\end{array}$ & $R^{2}$ & $\begin{array}{l}\text { Cronbach's } \\
\text { Alpha }\end{array}$ \\
\hline Dynamic capability & 0.643 & 0.900 & 0.676 & 0.862 \\
\hline $\begin{array}{l}\text { Organizational innovation } \\
\text { performance }\end{array}$ & 0.543 & 0.871 & 0.516 & 0.827 \\
\hline $\begin{array}{l}\text { Knowledge sharing } \\
\text { capability }\end{array}$ & 0.669 & 0.890 & 0.466 & 0.840 \\
\hline $\begin{array}{l}\text { Potential absorptive } \\
\text { capability }\end{array}$ & 0.579 & 0.843 & & 0.764 \\
\hline $\begin{array}{l}\text { Realized absorptive } \\
\text { capability }\end{array}$ & 0.708 & 0.906 & 0.546 & 0.862 \\
\hline
\end{tabular}


The results of the reliability analysis show that the Cronbach's alpha coefficient is above 0.7 , and thus the results are reliable. As for the validity, the CR value is above 0.8 , so the model in this work has high composite reliability. The AVE is above 0.5 , which indicates that the latent variables have convergent validity. In addition, Hair, Anderson, Tatham, and Black (1998) pointed out that if the observed variable factor loading's absolute value (individual validity) is above 0.5 then it is within the acceptable range.

Discriminant validity describes the degree to which a variable is dissimilar to other variables. Chin (1998) noted that discriminant validity can be measured by calculating the square root of AVE for each variable, and the results should be greater than the covariance coefficient. The results for the correlation coefficient are shown in Table 2.

Table 2: Correlation table

\begin{tabular}{cccccc}
\hline & $\begin{array}{c}\text { Dynamic } \\
\text { capability }\end{array}$ & $\begin{array}{c}\text { Organizational } \\
\text { innovation } \\
\text { performance }\end{array}$ & $\begin{array}{c}\text { Knowledge } \\
\text { sharing } \\
\text { capability }\end{array}$ & $\begin{array}{c}\text { Potential } \\
\text { absorptive } \\
\text { capability }\end{array}$ & $\begin{array}{c}\text { Realized } \\
\text { absorptive } \\
\text { capability }\end{array}$ \\
\hline $\begin{array}{c}\text { Dynamic capability } \\
\text { Organizational inno- } \\
\text { vation performance }\end{array}$ & 0.956 & $0.723^{* * *}$ & 0.730 & & \\
$\begin{array}{c}\text { Knowledge sharing } \\
\text { capability }\end{array}$ & $0.719^{* *}$ & 0.632 & 0.660 & & \\
$\begin{array}{c}\text { Potential absorptive } \\
\text { capability }\end{array}$ & $0.795^{* *}$ & 0.728 & $0.702^{* *}$ & 0.868 & 0.772 \\
$\begin{array}{c}\text { Realized absorptive } \\
\text { capability }\end{array}$ & $0.473^{*}$ & 0.587 & $0.747^{*}$ & $0.683^{* * *}$ & \\
\hline$*: p<0.05 ; * *: p<0.01 ; * * *: p<0.001$ & & & &
\end{tabular}

For any two dimensions, the square root of AVE shows that the variables in the model are different for each dimension, which means that the questionnaire has sufficient individual validity. In sum, the results for the Cronbach's alpha coefficients, CR, and AVE values all correspond showing that the reliability and validity of the questionnaire, and thus the verification of the hypotheses and model can be carried out.

\section{Data Analysis and Testing}

PLS is employed to test hypotheses. The results of PLS are shown in Figure 2. Figure 2 shows that the five dimensions have strong explanatory power. The $R^{2}$ value $(0.676)$ of dynamic capability demonstrates it can be explained by knowledge sharing capability, realized absorptive capability, and potential absorptive capability. Moreover, the standardized path coefficient shows that "dynamic capability" has a positive and the most direct influence on "organizational innovation performance". Thus organizational dynamic capability positively affects organizational performance. The standardized path coefficient of "potential absorptive capability" to "dynamic capability" is 0.571 , a positive and direct influence, and thus potential absorptive capability positively influences dynamic capability. The standardized path coefficient of "realized absorptive capability" to "dynamic capability" is 0.307 . Realized absorptive capability positively influences dynamic capability. The standardized path coefficient of "potential absorptive capability" to "realized absorptive capability" is 0.614 . It is shown that potential absorptive capability and realized absorptive capability are positively related. Considering "sharing capability" as the moderator variable between "potential absorptive capability" and "realized absorptive capability", it is found that knowledge sharing influences potential absorptive capability and realized absorptive capability. 


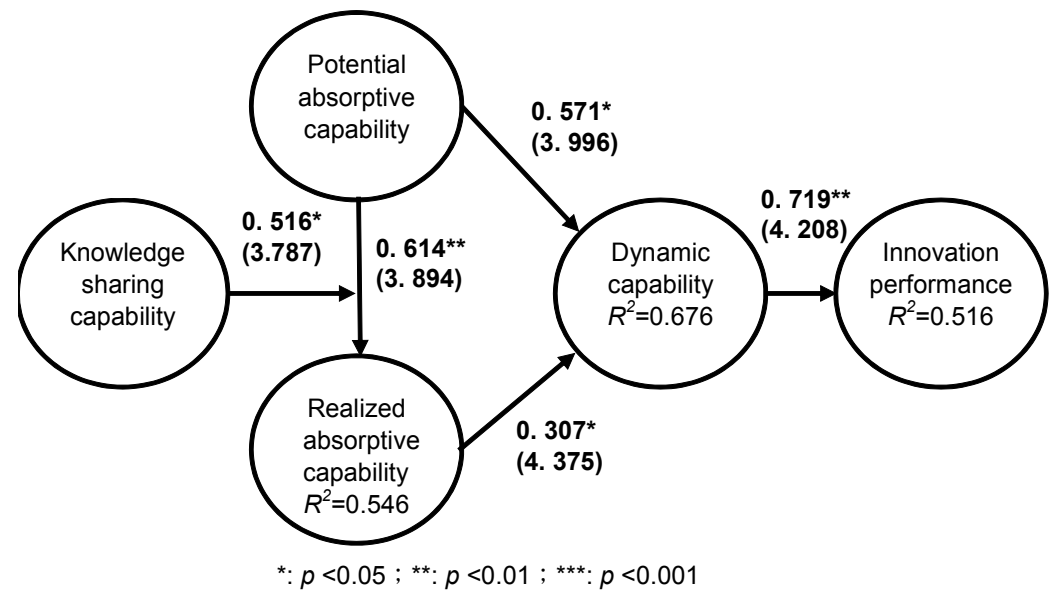

Figure 2: Empirical model with standardized path coefficients and t values

\section{Further Analysis}

Expenditures on R\&D impact a company's innovation capability and performance. National Science Council (NSC) of Taiwan stated that the average R\&D expenditures by Taiwanese companies have grown from $7.93 \%$ in 2003 to $12 \%$ in 2009 (National Science Council, 2010). In Taiwan, the manufacturing industry is mostly composed of small and medium-size companies, which implies that they make insufficient investments and face heavy R\&D costs. In general, R\&D expenditures account for $5 \%$ to $10 \%$ of total firm revenue, with more than $10 \%$ for R\&D oriented businesses. Only a few large companies in Taiwan have R\&D investments above $15 \%$ of revenue, and thus compared to international companies the level of R\&D investment is rather low. Based on the figures from the NSC of Taiwan for year 2010, the firms in this study are divided into two groups: 1) Low innovation investment companies (R\&D expenditures below $12 \%$ of revenue, $62 \%$ of the all respondent companies) and 2) High innovation investment companies (greater than $12 \%, 38 \%$ of the all respondent companies). We concentrate on the analysis of these two groups using different models to study the effects of knowledge integration on organizational innovation performance for different types of organizations.

From Figure 3, the path coefficient shows that "potential absorptive capability" has the greatest positive influence on "dynamic capability" (path coefficient equals of 0.732 ). With regard to the main focus of this study, the effects of knowledge management on organizational innovation performance, the path coefficient is only 0.667 , and thus, compared to the entire model, the knowledge management capability for a low innovation investment company has less influence on organizational innovation performance.

The structural model is examined using PLS for a cross-analysis of high innovation investment companies, and the results are shown in Figure 4. From Figure 4, the path coefficient shows that "potential absorptive capability" has the greatest positive influence on "realized absorptive capability" (the path coefficient is equal to 0.854 ). The effects of knowledge management on organizational innovation performance for a high innovation investment company are higher than those for low investment companies. We thus infer that high innovation investment companies are more able to use knowledge management capability to improve organizational innovation performance in order to sustain their competitive advantages. 


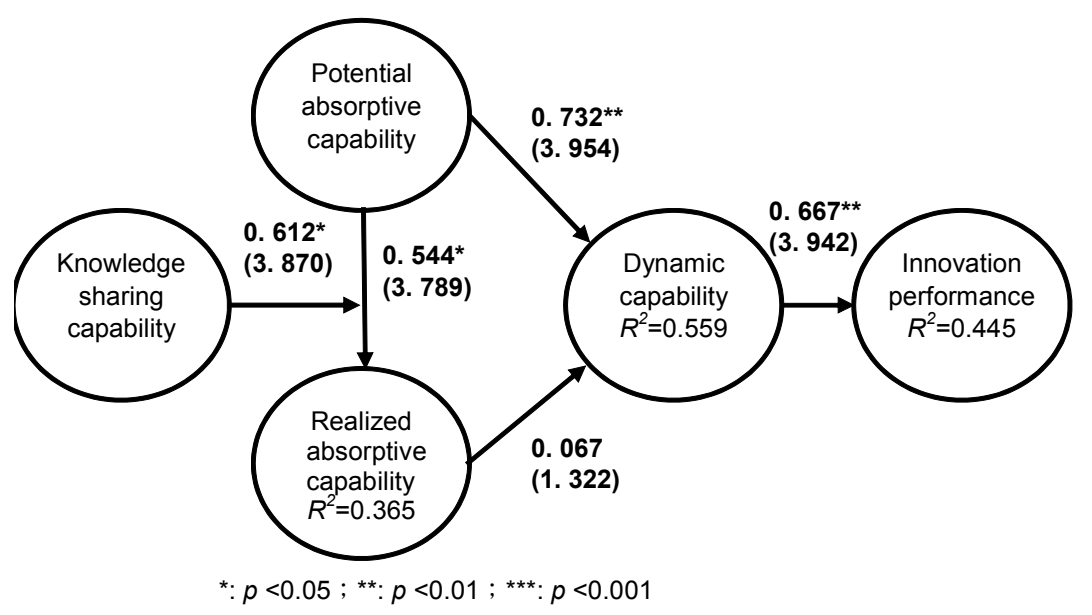

Figure 3: Structural model of low innovation investment companies with standardized path coefficients and $t$ values

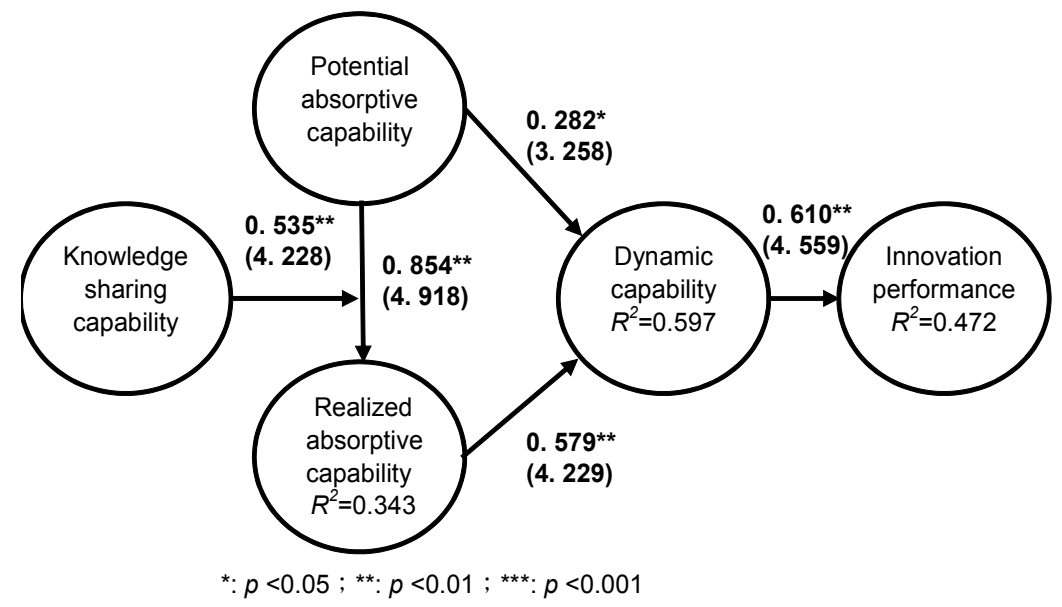

Figure 4: Structural model of high innovation investment companies with standardized path coefficients and $t$ values

\section{Discussion}

Hypothesis 1 is supported by the empirical results, and thus potential absorptive capability has a positive impact on dynamic capability. That is, if a company can improve its potential absorptive capability, it will be better able to acquire external knowledge more efficiently in order to reinforce or modify company strategy. However, when examining different types of businesses, the related path coefficient of low innovation and investment companies shows more influence than that of high innovation and investment companies. The main cause of this was explained by Zahra and George (2002b), who noted that potential absorptive capability includes knowledge acquisition capability and knowledge assimilation capability, as well as the efficient acquisition and exploitation of external knowledge in order to improve effective knowledge exploitation. In addition, Szulansli (1996) noted that different industrial backgrounds or organizational cultures have an influence the knowledge acquisition, assimilation, and value. Therefore, as low innovation investment companies lack internal resources and rely on external assistance, they are subject to a greater influence than other companies in this dimension. 
In addition, the results also show that potential absorptive capability is not only influenced by the knowledge acquisition capability and knowledge absorptive capability, but also by the industrial background and organizational culture of a firm. The main advantage of potential absorptive capability is that it can help a company to improve its operational knowledge and technical ability with knowledge transfer, licensing, or purchase from external resources.

Hypothesis 2 is supported by the empirical results, showing that realized absorptive capability has a positive impact on dynamic capability. That is, if the realized absorptive capability is improved, it will aid the development of dynamic capability and enable the firm to respond to a rapidly changing environment. However, when examining different types of businesses, high innovation investment companies were more influenced by dynamic capability than low innovation investment ones.

Zahra and George (2002a, 2002b) pointed out that realized absorptive capability includes knowledge transfer capability and knowledge exploitation capability, while Christensen, Suarez, and Utterback (1998) noted that efficient knowledge exploitation helps to reinforce competitiveness in high-technology companies that rely on research innovation. In support of this, the results of this study and other recent research show that high innovation investment companies require realized absorptive capability more than low innovation investment ones. The advantage of realized absorptive capability is that it can help an enterprise to combine internal and external knowledge, and the introduction of the latter will help companies to create their own knowledge and can positively influence their innovation abilities.

Hypothesis 3 is also supported. Potential absorptive capability positively influences the realized absorptive capability. When examining different types of businesses, the path coefficient of high innovation investment companies is greater than the one for low innovation investment firms, and this is because the model for low innovation and research companies has less explanatory power in the dimension of realized absorptive capability.

Based on the perspective of knowledge absorptive capability, knowledge acquisition and assimilation capability are more important than staff learning motivation. However, when the two measures are close, this means that the company recognizes the importance of internal learning motivation with regard to the knowledge absorptive capability. Hypothesis 4 is supported by the empirical results, indicating that when the ratio of the realized absorptive capability to the potential absorptive capability is high, this means that the organization is able to use the acquired knowledge efficiently. In addition, the more knowledge is shared in an organization, the more potential absorptive capability influences the realized absorptive capability, and the impact is similar in firms with both high and low levels of innovation investment.

The empirical results show that dynamic capability has the greatest model explanatory power, and the standardized path coefficient shows that dynamic capability has a positive and direct influence on organizational innovation performance and so it has a positive correlation with organizational performance. These results were same for firms with both high and low levels of innovation investment.

According to Henderson and Cockburn (1994), dynamic capability creates competitive advantage when associated with other resources. Teece et al. (1997) defined dynamic capability as a firm's ability to integrate, build, and reconfigure internal and external competences to address rapidly changing environments. Knowledge integration is when a company brings in external resources or extra profit by leveraging WHAT, while knowledge transfer is the ability to readjust and adapt company fitness. 


\section{Conclusion}

This paper builds a conceptual model of the effects of knowledge management on organizational innovation performance and proposes five hypotheses. The relationships among latent variables are verified through PLS. The analysis results show that dynamic capability has a positive and the most direct influence on organizational innovation performance. Therefore, there is a positive correlation between dynamic capability and organizational performance. According to Teece et al. (1997), dynamic capability is a firm's ability to integrate, build, and reconfigure internal and external competences in order to deal with rapidly changing environments. Meanwhile, the results of this study show that dynamic capability can help a firm to integrate or transfer the organization positions, processes, knowledge, or skills needed in order to address to the changing needs of the market. Also, knowledge integration and transformation capability are needed to improve a firm's organizational innovation performance, and this performance will be influenced along with changes of dynamic capability; in other words, the greater dynamic capability is, the greater the organizational innovation performance will be.

In management practice, if the potential absorptive capability is improved, external knowledge will be easily acquired in order to adapt the company's operational strategy, and the resulting improvement in absorptive capability will drive the growth of dynamic capability in order to better deal with a rapidly changing environment. To improve organizational innovation performance by using knowledge management, this paper suggests: 1 . The realized absorptive capability can be used to help an enterprise combine internal and external knowledge. The introduction of external knowledge will help the enterprise to create its own knowledge or will positively influence its innovation ability. 2. The transfer, licensing, or purchasing of external knowledge and application of it in the enterprise can moderate the buffer time for knowledge assimilation and integration.

As the survey is executed from Taiwan's top five hundred manufacturing companies, which are characterized of OEM oriented, skillful, knowledge-intensive, and innovation research, and the research timeline differs from one and other. Therefore, although dynamic capability facilitates the improvement of organizational innovation performance, some differences persist in the studied documents.

\section{References}

Anderson, J. C., \& Gerbing, D. W. (1988). Structural equation modeling in practice: A review and recommended two-step approach. Psychological Bulletin, 103(3), 411-423.

Byrne, B. M. (1994). Structural Equation Modeling with EQS and EQS/Windows. Newbury Park, CA: Sage.

Chandran, J. P. (2004). Managing new industry creation: Global knowledge formation and entrepreneurship in high technology. The Academy of Management Review, 29(2), 303-306.

Chesbrough, H.W. (2003). Open Innovation: The New Imperative for Creating and Profiting from Technology. New York: Harvard Business School Press.

Chin, W. W. (1998). Issues and opinion on structural equation modeling. Management Information System Quarterly, 22(1), 52-62.

Christensen, C. M., Kaufman, S. P., \& Shih, W. C. (2008). Innovation killers. Harvard Business Review, 86(1), 98-105.

Christensen, C. M., Suarez, F. F., \& Utterback, J. M. (1998). Strategies for survival in fast changing industries. Management Science, 44(12), S207-S220.

Cohen, W. N., \& Levinthal, D. A. (1990). Absorptive capability: A new perspective on learning and innovation. Administrative Science Quarterly, 35, 1128-1152. 
Cooper, R. G., \& Kleinschmidt, E. J. (1996). Winning business in product development: The critical success factors. Research-Technology Management, 39, 18-29.

Dechant, K.,\& Marsick, V. J.(1993). Team learning survey and facilitator guide. King of Prussia, PA: Organization Design \& Development.

Demarest, M. (1997). Understanding knowledge management. Long Range Planning, 30(3), 374-384.

Fornell, C., \& Larcker, D. F. (1981). Evaluating structural equation models with unobservable and measurement errors. Journal of Marketing Research, 18, 35-50.

Gan, B. P., Liow, L. F., Gupta, A. K., Lendermann, P. Turner, S. J., \& Wang, X. (2007). Analysis of a borderless fab using interoperating AutoSched AP models. International Journal of Production Research, $45(3), 675-697$.

Hair, J. F., Anderson, R. E., Tatham, R. L., \& Black, W. C. (1998). Multivariate data analysis. New York: Prentice-Hall.

Hayduk, L.A. (1987). Structural Equation Modeling with LISREL: Essentials and advantage. Baltimore: Johns Hopkins University Press.

Helfat, C. E., \& Peteraf, M. A. (2003). The dynamic resource-based view: Capability lifecycles. Strategic Management Journal, 24, 997-1010.

Henderson, R., \& Cockburn, I. (1994). Measuring competence? Exploiting firm effects in pharmaceutical markets research. Strategic Management Journal, 15, 63-84.

Johnson, W. H. A., \& Johnston, D. A. (2004). Organizational knowledge creating processes and the performance of university-industry collaborative R\&D projects. International Journal of Technology Management, 27, 93-114.

Liao, S. H., \& Wu, C. C. (2010). System perspective of knowledge management, organizational learning, and organizational innovation. Expert Systems with Applications, 37(2), 1096-1103.

Luo, Y., (2000). Dynamic capabilities in international expansion. Journal of World Business, 35(4), 355378.

March, J., \& Simon, H. A. (1958). Organizations. New York: John Wiley.

Matthyssens, P., Vandenbempt, K., \& Berghman, L. (2006). Value innovation in business markets: Breaking the industry recipe. Industrial Marketing Management, 35(6), 751-761.

National Science Council. (2010). White Paper on Science and Technology, 2010. National Science Council, Republic of China.

Nonaka, I. (1991). The knowledge creating company. Harvard Business Review, 11(12), 96-104.

Nonaka, I., \& Konno, N. (1998). The concept of "Ba": Building a foundation for knowledge creation. California Management Review, 40(3), 40-54.

Nonaka, I., \& Takeuchi, H. (1995). The knowledge-creating company: How Japanese companies create the dynamics of innovation. New York: Oxford University Press.

Olson, E. M., Walker, O. C., \& Ruekert, R. W. (1995). Organizing for effective new product development: The moderating role of product innovativeness. Journal of Marketing, 1, 48-62.

Orfila-Sintes, F., \& Mattsson, J. (2009). Innovation behavior in the hotel industry. Omega, 37(2), 380-394.

Peteraf, M. A. (1993). The cornerstones of competitive advantage: A resource-based view. Strategic Management Journal, 14(3), 179-192.

Quinn, J. B., Anderson, P., \& Finkelstein, S. (1996). Managing professional intellect: Making the most of the best. Harvard Business Review, 74(2), 71-80.

Ringle, C. M., Wende, S., \& Will, A. (2005). SmartPLS - Version 2.0. Hamburg University, Hamburg

Roberts, B. (2000). Pick employees' brains. HR Magazine, 45(2), 115-120. 
Spender, J. C. (1996). Making knowledge the basis of a dynamic theory of the firm. Strategic Management Journal, 17, 45-62.

Storey, J., Emberson, C., Godsell, J., \& Harrison, A. (2006). Supply chain management: Theory, practice and future challenges. International Journal of Operations \& Production Management, 26(7), 754774.

Szulanski, G. (1996). Exporting internal stickiness: Impediments to the transfer of best practice within the firm. Strategic Management Journal, 17, 27-33.

Tsai, M. T. (2010). Innovation capability and performance in Taiwanese Science Parks: Exploring the moderating effects of industrial clusters fabric. The International Journal of Organizational Innovation, 2(4), 80-103.

Teece, D. J. (1986). Transaction cost economics and the multinational enterprise. Journal of Economic Behavior and Organization, 7, 21-45.

Teece, D. J., Pisano, G., \& Shuen, A. (1997). Dynamic capabilities and strategic management. Strategic Management Journal, 18(7), 509-533.

Veugelers, R., \& Cassiman, B. (1999). Make and buy in innovation strategies: Evidence from Belgian manufacturing firms. Research Policy, 28, 63-80.

Voss, C. A. (1992). Measurement of innovation and design performance in service. Design Management Journal, 3(1), 40-46.

Wiig, K. M. (1997). Knowledge management: Where did it come from and where will it go? Expert Systems with Applications, 14(5), 67-78.

Wingwon, B. (2012). Effects of entrepreneurship, organization capability, strategic decision making and innovation toward the competitive advantage of SMEs enterprises. Journal of Management and Sustainability, 2(1), 137-150.

Wu, W. W. (2007). Exploring the critical patterns of top 1000 corporate rankings across the Taiwan strait using the PLS. East-Asia Review, 457, 12-23.

Zahra, S. A., \& George, G. (2002a). Absorptive capability: A review, reconceptualization, and extension. Academy of Management Review, 27(2), 185-203.

Zahra, S. A., \& George, G. (2002b). The net-enabled business innovation cycle and the evolution of dynamic capabilities. Information System Research, 13(2), 147-150.

Zeng, C. W., \& Hsu, C. L. (2008). The study of user participation in blog: Social capital theory perspective. Journal of Cyber Culture and Information Society, 15, 209-232

Zollo, M., \& Winter, S. (2002). Deliberate learning and the evolution of dynamic capabilities. Organization Science, 13, 339-351. 


\section{Biographies}

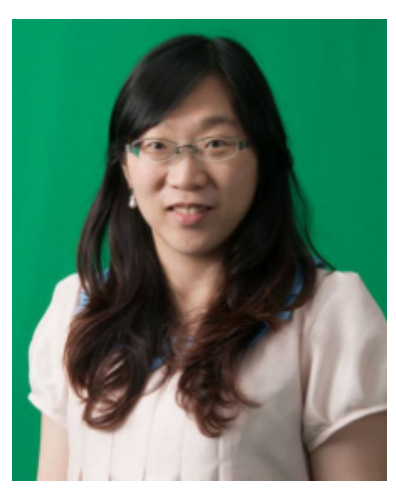

Fan-Yun Pai is Associate Professor of Department of Business Administration received her $\mathrm{PhD}$ degree in Business Administration from National Taiwan University in 2008. Dr. Pai's research interests include supply chain management and B2B marketing. She has published articles in Industrial Marketing Management, Technological Forecasting and Social Change, International Journal of Production Research, Production Planning and Control, Expert Systems with Applications, International Journal of Production Economics, Quality and Quantity, and the Service Industry Journal, etc.

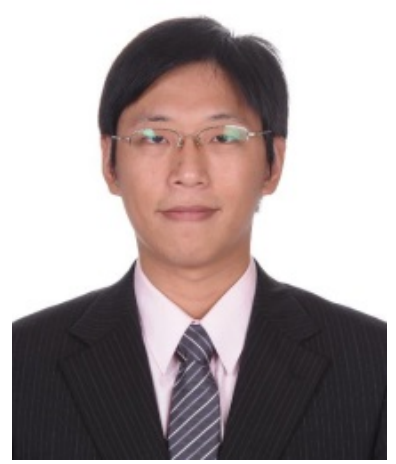

Hung-Fan Chang is a factory assistant manager. $\mathrm{He}$ is a $\mathrm{PhD}$ candidate in the Institute of Management of Technology at National Chiao Tung University in Taiwan. His research interests include management of technology and innovation management. He is a member of IEEE and CSMOT. 